\title{
Evaluation of the effect of two active warming and humidifying high-flow oxygen therapy systems in patients with tracheotomy
}

\author{
MEI YANG, YI SONG, LU PAN and XIAOHUA XIE \\ Department of Critical Care, The First Affiliated Hospital of Shenzhen University, \\ Shenzhen Second People's Hospital, Shenzhen, Guangdong 518035, P.R. China
}

Received January 2, 2019; Accepted May 22, 2019

DOI: $10.3892 /$ br.2019.1219

\begin{abstract}
The present study evaluated the effect of two active warming and humidifying high-flow oxygen therapy systems in patients with tracheotomy, in order to provide a basis for selecting the method of humidification oxygen therapy for tracheotomy. A total of 78 patients with tracheotomy, who underwent surgery between July 2017 and December 2017, were randomly divided into an observation group (39 patients) and a control group (39 patients). Patients in the observation group were treated with artificial airway high-flow humidification oxygen therapy in a closed suction system. Patients in the control group were treated using a respiratory humidification therapy device. Changes of sputum viscosity, pulmonary infection, arterial oxygen partial pressure $\left(\mathrm{PaO}_{2}\right)$, arterial blood carbon dioxide partial pressure $\left(\mathrm{PaCO}_{2}\right)$ and arterial oxygen saturation $\left(\mathrm{SaO}_{2}\right)$ were observed at 0,48 and $96 \mathrm{~h}$, and 7 days following oxygen therapy. The sputum viscosity and lung infection in the observation group were lower than those in the control group at 48, $96 \mathrm{~h}$ and 7 days following oxygen therapy, and the $\mathrm{PaO}_{2}$ and $\mathrm{SaO}_{2}$ were higher in the observation group than in the control group, which was statistically significant $(\mathrm{P}<0.05)$. However, there was no statistically significant difference $(\mathrm{P}>0.05)$ in $\mathrm{PaCO}_{2}$ between the two groups. In conclusion, the artificial airway high-flow humidification oxygen therapy closed suction system was considered more suitable for long-term oxygen therapy of tracheotomy patients than the respiratory humidification therapy device. It can improve airway humidification and oxygen levels at lower equipment and consumable costs. The effects of treatment aim to reduce lung infections, which have clinical implications to a certain extent.
\end{abstract}

Correspondence to: Dr Xiaohua Xie, Department of Critical Care, The First Affiliated Hospital of Shenzhen University, Shenzhen Second People's Hospital, 3002 Sungang West Road, Shenzhen, Guangdong 518035, P.R. China

E-mail: 13560779836@163.com

Key words: oxygen therapy, humidification, high flow rate, tracheotomy

\section{Introduction}

The establishment of an artificial airway, including tracheal intubation or tracheotomy, is an important measure to rescue and treat critically ill patients. When the artificial airway is established, there is no upper respiratory tract warming or humidification. As the warming and humidifying function of the upper respiratory tract is lost, ciliary tracheal mucosal damage occurs, the mucociliary transport function is lost, and secretion is thickened and difficult to discharge. Humidification functions in preventing hypothermia; warming and humidification are crucial in preventing hypothermia, destruction of respiratory epithelial tissue, bronchospasm, atelectasis and airway obstruction (1). The 2012 American College of Respiratory Therapy Airway Wetness Guidelines (1) propose that, in order to ensure the normal activity of the mucociliary system, the gas inhaled through the artificial airway must be at normal body temperature $\left(37^{\circ} \mathrm{C}\right)$ and relative humidity (100\%), which is absolute humidity (44 mg/l). The 2017 British Thoracic Society guidelines for adult oxygen use suggest that patients who require long-term oxygen therapy ( $>24 \mathrm{~h}$ ) for tracheotomy may be considered for the use of a large volume oxygen humidification device, particularly for patients with poor discharge of secretions (2). In recent years, clinical researchers have used respiratory humidification therapy devices with an active warming humidifier (MR850, Fisher \& Paykel Healthcare, Auckland, New Zealand), heating pipelines and Venturi high-flow humidification oxygen therapy equipment to treat patients with tracheotomy. Clinical studies on the use of respiratory humidification therapies for tracheotomy patients are limited. Corley et al (3) and others used high flow nasal cannula (HFNC) high-flow oxygen therapy and low-flow oxygen therapy with T-tubes in a tracheotomy. High-flow oxygen therapy improves the patient's oxygen, and ivolves a different mechanism of action between the transnasal and transtracheal incision modes of delivery; thus, we maintained a certain positive ventilation pressure. High-flow oxygen therapy in the tracheotomy patient bypasses the larynx. The upper and lower respiratory tract may affect the clinical effect of HFNC. The Venturi humidification oxygen therapy system regulates the flow rate of gas, mainly by adjusting the oxygen flow rate and the oxygen concentration standard of the Venturi air oxygen mixer; however, the precise mechanism of its operation remains controversial (4). In view of the above 
research status in the actual application process, it is clear that there are differences in the effects of humidification and ventilation between the two oxygen therapy methods in patients with tracheotomy. In order to further examine the effects, evaluation of the two humidification oxygen therapy methods is required to provide more choice.

The aim of the present study was to further examine the effect of the two humidification oxygen therapy methods. This involved use of a respiratory humidification therapy device and a high-flow humidification oxygen therapy device to treat patients with tracheotomy.

\section{Materials and methods}

Setting. The present study was conducted at the Department of Critical Care, with 39 beds in total, of Second People's Hospital of Shenzhen (First Affiliated Hospital of Shenzhen University, Shenzhen, China), Shenzhen is one of the largest cities and the most populous city in South China. The study protocol was approved by the Ethics Committee of the Department of Critical Care, Second People's Hospital of Shenzhen (Shenzhen, China).

Patients. In total, 78 patients with tracheotomy in the intensive care unit (ICU) were recruited to the study between July 2017 and December 2017, who were randomly divided into an observation group $(n=39)$ and a control group $(n=39)$. The baseline characteristics are shown in Table I. All tracheotomy patients who met the inclusion criteria of the ICU underwent respiratory humidification immediately, within $24 \mathrm{~h}$ of being offline. Patients who had been taken offline in the ICU were randomly assigned to the control group and the observation group within $24 \mathrm{~h}$. The inclusion criteria were as follows: i) 16-80 years old; ii) tracheal incision patients evacuated from the ventilator; iii) APACHE II score $\geq 15$ points (5). The exclusion criteria were as follows: i) Patients with a history of chronic respiratory diseases, patients with chronic respiratory diseases due to long-term chronic inflammation, repeated use of antibiotics and patients in an immunosuppressive state. The use of high-flow humidification oxygen therapy to improve airway humidification cannot be used as an independent factor affecting the lungs of patients with an infection, as the experimentally set observation indicators are not specific to such patients; ii) patents with a history of airway injury, lung trauma or lung surgery; iii) patients with body temperature $<35^{\circ} \mathrm{C}$, and those with stage 4 heart failure patients requiring fluid restriction (6); iv) pregnant woman. There were no significant differences in gender, age, diagnosis or condition between the two groups $(\mathrm{P}>0.05)$.

Oxygen therapy. When the patients in the observation group had been evacuated from the ventilator, the artificial airway high-flow humidification oxygen therapy closed suction system was used for oxygen therapy, and the gas flow rate was adjusted according to the patient's requirements. The artificial airway high-flow humidification oxygen therapy closed suction system is composed of an automatic pressure regulating oxygen flow meter, a Fisher \& Paykel MR850 automatic temperature control heating system, a Venturi air oxygen mixing valve (Fisher \& Paykel Healthcare Ltd.), oxygen connecting tube (Fisher \& Paykel Healthcare Ltd.), RT308 heating breathing tube (Fisher \& Paykel Healthcare Ltd.), screw joint (EM07-005, Excellentcare Medical Ltd.) and a Closed Suction System (Tracheostomy; Pacific Hospital Supply Co. Ltd.) (Fig. 1). The output gas flow rate in the oxygen therapy system was adjusted to $\geq 401 / \mathrm{min}$. The humidifier was used in invasive mode to set up the output temperature of the screw joint at $37^{\circ} \mathrm{C}$, and the relative humidity at $100 \%$.

When patients in the control group had been evacuated from the ventilator, the respiratory humidification therapy device was used for oxygen therapy, and the gas flow rate was adjusted according to the patient's requirements. A Fisher \& Paykel AIRVO2 (Fig. 2) respiratory humidification therapy device and specific heating tube were used to adjust the therapeutic instrument output gas flow rate $\geq 401 / \mathrm{min}$ and the output gas temperature at $37^{\circ} \mathrm{C}$.

Oxygen therapy equipment features. There was no difference in equipment quality as both equipment and piping were obtained from Fisher \& Paykel Healthcare. Both types of oxygen therapy are high-flow oxygen supply systems supplying gas at a flow rate of $\geq 40 \mathrm{l} / \mathrm{min}$, which is higher than patient inspiratory flow rate and can meet the demand of a high-flow oxygen supply system (7). In addition, both contain an MR850 automatic temperature control heating system to control the temperature at $37^{\circ} \mathrm{C}$. The differences between the systems are as follows: The respiratory humidification therapy device can be used for nasal and tracheal incision; the gas flow rate is accurate and is not affected by the attached equipment; the pipeline and the extension pipe joint material are provided with water-permeable and airtight technology to effectively prevent condensed water inside the pipe; the output gas temperature is maintained at $37^{\circ} \mathrm{C}$, thus no external heating wire is required. The artificial airway humidification oxygen therapy system is only used for tracheotomy patients; the high-speed gas mainly depends on the automatic pressure regulating oxygen flow meter and the Venturi effect, whereas the gas flow rate is affected by the attached equipment; the pipeline and the extension pipe joint material do not have water-permeable and airtight technology, which produces a small volume of condensed water; the output gas temperature is maintained at $37^{\circ} \mathrm{C}$ under the control of an external heating wire.

The humidification system used an MR850 heating system, which comprises a humidification chamber and a heated-wire circuit; the gas maintained the temperature of the water leaving the chamber at $37^{\circ} \mathrm{C}$; the airway end temperature is automatically controlled to $40^{\circ} \mathrm{C}$ when breathing through the heated-wire circuit; the temperature of the connecting tube through the closed suction tube is $3^{\circ} \mathrm{C}$ lower. Eventually, the temperature at which the patient's airway enters the patient is exactly $37^{\circ} \mathrm{C}$ and the absolute humidity is $44 \mathrm{mg} / 1$. These setting differences enabled a higher inspiratory absolute humidity in the present study. For the Airvo 2, only the chamber temperature was set, at $37^{\circ} \mathrm{C}$. The Airvo 2 servo-controls the proximal temperature at $\sim 40^{\circ} \mathrm{C}$.

Compared parameters. Changes in sputum viscosity, arterial oxygen partial pressure $\left(\mathrm{PaO}_{2}\right)$, arterial blood carbon dioxide partial pressure $\left(\mathrm{PaCO}_{2}\right)$ and arterial oxygen saturation $\left(\mathrm{SaO}_{2}\right)$, 
Table I. Comparison of sputum viscosity in the control and experimental groups.

\begin{tabular}{|c|c|c|c|c|c|c|c|c|}
\hline \multirow[b]{2}{*}{ Sputum viscosity } & \multicolumn{2}{|c|}{$0 \mathrm{~h}$} & \multicolumn{2}{|c|}{$48 \mathrm{~h}$} & \multicolumn{2}{|c|}{$96 \mathrm{~h}$} & \multicolumn{2}{|c|}{7 days } \\
\hline & Control & Observation & Control & Observation & Control & Observation & Control & Observation \\
\hline Grade I & 7 & 8 & 5 & 6 & 4 & 3 & 2 & 3 \\
\hline Grade II & 26 & 25 & 18 & 28 & 19 & 30 & 18 & 31 \\
\hline Grade III & 6 & 6 & 16 & 5 & 16 & 6 & 19 & 5 \\
\hline Z-score & 0.086 & & 8.027 & & 6.457 & & 11.816 & \\
\hline P-value & 0.958 & & 0.018 & & 0.040 & & 0.003 & \\
\hline
\end{tabular}

in addition to the incidence of lung infection were observed at $0,48,96 \mathrm{~h}$ and 7 days after oxygen therapy.

The arterial blood used for blood gas analysis was usually drawn from the patient's wrist by a nurse in the ICU, who was trained to do so $0,2,4$ and 7 days after weaning from the mechanical ventilation. Prior to the arterial blood gas test, the nurse applied pressure to the arteries in the patient's wrist for several seconds. The procedure, known as the modified Allen test, assesses whether blood flow to the hand is normal. Once an artery is located, a needle is inserted into the artery and blood is draw. When the sample is obtained, care is taken to eliminate visible gas bubbles, as these bubbles can dissolve into the sample and lead to inaccurate results. The sealed syringe is taken to a blood gas analyzer and the sample is analyzed within $30 \mathrm{~min}$. The machine aspirates this blood from the syringe and measures the $\mathrm{pH}$ and the partial pressures of oxygen and carbon dioxide. The bicarbonate concentration is also calculated. These results are usually available for interpretation within 5 min.

Sputum viscosity grade determination. As the artificial airway, the patients were randomly assigned to receive either the high-flow humidification oxygen therapy closed suction system or the AIRVO 2 humidifier (Fisher \& Paykel Healthcare) with the tracheostomy interface at the onset of weaning from mechanical ventilation (time 0 ). Nurses in the ICU were trained to perform tracheostomy management, including suctioning and oral hygiene. The sputum samples were collected by suction using a sterile technique $0,2,4$ and 7 days after weaning from mechanical ventilation. The suction procedure was based on current knowledge. A sterile suction catheter was gently inserted into the endotracheal tube for a maximum of $15 \mathrm{~cm}$ or until resistance was detected; the duration of the suctioning procedure was limited to $<15 \mathrm{sec}$. The suctioning procedure was performed according to clinical requirements, only when secretions were present. Sputum viscosity was measured by the trained nurse, who performed the first suctioning on each day. The sputum viscosity was divided into three grades: Grade I: Diluted like rice soup or foam, no sputum retention on the inner wall of the tube following suction; grade II: Moderate adhesion, following suction, a small quantity of sputum is retained in the inner wall of the tube, but is easily removed by washing with water; grade III: Sticky and yellow, a large amount of adhesive remains on the inner wall of the suction tube, which is not easily removed by washing with water (7).
Pulmonary infection determination. The secretions in the artificial airway were collected in a blinded manner, and the sputum culture was detected by quantitative analysis. Pathogens in the lower respiratory tract secretions of $>10^{7} \mathrm{cfu} / \mathrm{ml}$ and reference to X-ray chest imaging examination confirmed the occurrence of new pulmonary infection (8). The detection time should be between $48 \mathrm{~h}$ and 7 days following oxygen therapy (9). In the present study, pulmonary infection was defined as pneumonia occurring between $48 \mathrm{~h}$ and 7 days after oxygen therapy. Pneumonia was defined of the presence of a new infiltrate (due to any pneumonia-causing pathogen) on chest radiograph (CXR) and one or more clinical symptoms, including fever, a new cough and dyspnea. The CXRs were interpreted by a panel of radiologists trained in the standardized interpretation of CXRs. The CXRs were classified as either demonstrating consolidation, another infiltrate, both consolidation and another infiltrate, or as being normal or uninterpretable. Standard culture methods were used to detect putative pneumonia pathogens from sputum samples for the purpose of ascribing etiology. A sterile mucus extracting catheter attached to a suction device was gently inserted into the endotracheal tube for a maximum of $15 \mathrm{~cm}$ or until resistance was detected (the duration of the suctioning procedure was limited to $<15 \mathrm{sec}$ ) and sputum was collected into a sterile trap. The suctioning procedure was performed according to clinical requirements (only when secretions are present). The sputum specimens were immediately sent to the laboratory and were washed with saline. The presence of $>25$ white blood cells and $<10$ epithelial cells per low-power field of vision was regarded as being indicative of a high-quality specimen. The sputum was separated from the mucus by adding approximately five times the volume of saline, following which the saline was removed by the suction tube. Following the addition of the same volume of sputum pretreatment solution, each specimen was diluted to $10^{6} \mathrm{cfu} / \mathrm{ml}$ of the original concentration and inoculated into a blood dish, a Chinese blue dish and a chocolate dish. Colony count and bacterial type identification were performed using a Bact Alert 3D full-automatic culture device (bioMérieux, Inc.) following incubation for $18 \mathrm{~h}$ in the conditions of $5 \% \mathrm{CO}_{2}$ and $37^{\circ} \mathrm{C}$.

Statistical analysis. Statistical analysis was performed using the SPSS 17 software package (SPSS, Inc.). All data are presented as the mean \pm standard deviation, and the difference between two groups were compared with a t-test. The rank sum test was used for rank data and the $\chi^{2}$ test was used 


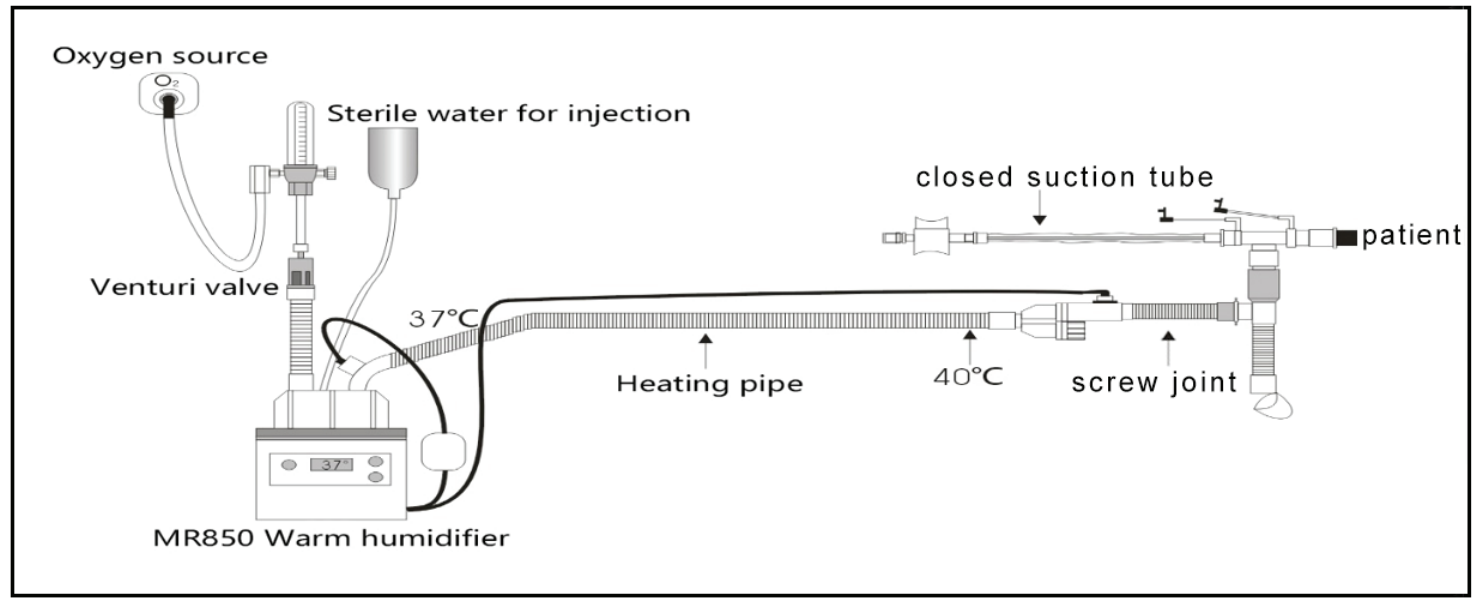

Figure 1. Artificial airway high-flow humidification oxygen therapy closed suction system and AIRVO 2 humidifier.

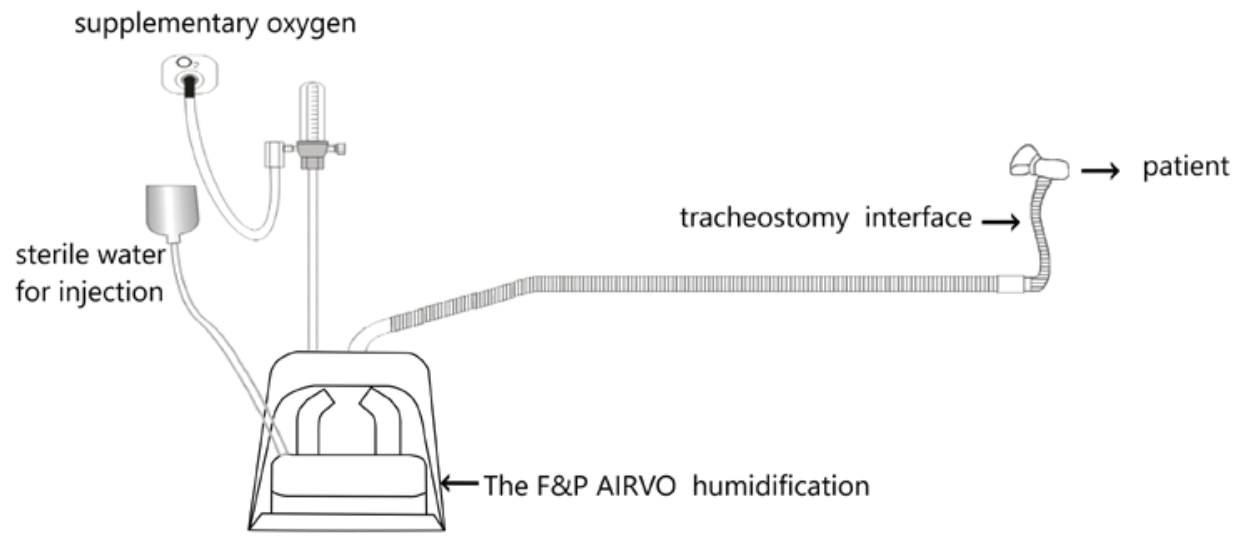

F\&P AIRVO2 respiratory humidification therapy device

Figure 2. F\&P AIRVO2 respiratory humidification therapy device.

for enumeration data. $\mathrm{P}<0.05$ was considered to indicate a statistically significant difference.

\section{Results}

Patients. A total of 78 patients were initially included in the study, and all patients were successfully taken offline, in which the patients were disconnected from the ventilator and allowed to breath unassisted through the tracheostomy cannula.

Sputum viscosity in the control and experimental groups. The sputum viscosity did not differ significantly between the two groups on finishing oxygen therapy $(\mathrm{P}>0.05)$. However, the number of patients with grade III sputum viscosity in the control group was increased 48,96 h and 7 days after oxygen therapy, and the sputum viscosity grade between the two groups was statistically significant $(\mathrm{P}<0.05)$ at the detected time points.

Incidence of pulmonary infection in the control and observation groups. Those patients who acquired a pulmonary infection in the two groups $48 \mathrm{~h}$ and 7 days after oxygen therapy are shown in Table III. The number of new pulmonary infections in the control group significantly increased within 7 days after taken offline compared with the observation group (Table II). In the control group, there were 13 cases of pulmonary infection. In the observation group, there were five cases of pulmonary infection. The incidence of pulmonary infection between the two groups was statistically significant. Significant differences between the control and observation groups 48, $96 \mathrm{~h}$, and 7 days after oxygen therapy were observed $(\mathrm{P}=0.018,0.040$ and 0.003 , respectively; Table I).

Blood gas indices in the control and observation groups. Blood gas analysis can provide a more comprehensive understanding of the patient's ventilation function. Ventilation function mainly depends on hypoxia and $\mathrm{CO}_{2}$ retention, and the acid-base state and electrolyte imbalance in the body when oxygen therapy finishes. No significant differences were observed in the $\mathrm{PaO}_{2}, \mathrm{PaCO}_{2}$ or $\mathrm{SaO}_{2}$ between the two groups $(\mathrm{P}>0.05)$. After 48, $96 \mathrm{~h}$ and 7 days, the $\mathrm{PaO}_{2}$ gradually approached the normal range in the control group, and the $\mathrm{SaO}_{2}$ also exhibited a downward trend, whereas the $\mathrm{PaCO}_{2}$ did not change $(\mathrm{P}<0.05)$. The $\mathrm{PaO}_{2}$ and $\mathrm{SaO}_{2}$, but not the $\mathrm{PaCO}_{2}$, differed significantly between the two groups $(\mathrm{P}>0.05)$. 
Table II. Incidence of pulmonary infection in the control and observation groups.

Pulmonary infection

\begin{tabular}{|c|c|c|c|c|}
\hline \multirow[b]{2}{*}{ Group } & & \multirow[b]{2}{*}{$\chi^{2}$ value } & \multirow[b]{2}{*}{ P-value } \\
\hline & Positive, n (\%) & Negative, n (\%) & & \\
\hline Control (n=39) & $13(33.3)$ & $26(66.7)$ & 4.622 & 0.032 \\
\hline Observation $(n=39)$ & $5(12.8)$ & $34(87.2)$ & & \\
\hline
\end{tabular}

Table III. Blood-gas indices in the control and observation groups.

\begin{tabular}{|c|c|c|c|c|c|}
\hline Index & Group & $0 \mathrm{~h}$ & $48 \mathrm{~h}$ & $96 \mathrm{~h}$ & 7 days \\
\hline \multirow[t]{4}{*}{$\mathrm{PaO}_{2}(\mathrm{mmHg})$} & Control & $91.56 \pm 6.07$ & $87.08 \pm 6.74$ & $86.20 \pm 5.69$ & $86.84 \pm 6.50$ \\
\hline & Observation & $92.46 \pm 6.98$ & $93.23 \pm 6.76$ & $94.46 \pm 6.34$ & $97.00 \pm 6.63$ \\
\hline & F-value & 0.606 & 4.025 & 6.054 & 7.373 \\
\hline & P-value & 0.546 & $<0.001$ & $<0.001$ & $<0.001$ \\
\hline \multirow[t]{4}{*}{$\mathrm{PaCO}_{2}(\mathrm{mmHg})$} & Control & $36.21 \pm 1.42$ & $37.38 \pm 1.79$ & $37.18 \pm 1.68$ & $36.74 \pm 1.57$ \\
\hline & Observation & $36.95 \pm 2.22$ & $36.97 \pm 1.55$ & $37.00 \pm 1.56$ & $36.89 \pm 1.59$ \\
\hline & F-value & 1.761 & 1.084 & 0.489 & 0.431 \\
\hline & P-value & 0.082 & 0.282 & 0.626 & 0.668 \\
\hline \multirow[t]{4}{*}{$\mathrm{SaO}_{2}(\%)$} & Control & $96.94 \pm 1.56$ & $96.25 \pm 1.14$ & $95.72 \pm 1.48$ & $94.85 \pm 1.41$ \\
\hline & Observation & $97.33 \pm 1.54$ & $97.89 \pm 1.35$ & $97.85 \pm 1.55$ & $97.42 \pm 1.98$ \\
\hline & F-value & 1.096 & 5.791 & 6.218 & 6.593 \\
\hline & P-value & 0.277 & $<0.001$ & $<0.001$ & $<0.001$ \\
\hline
\end{tabular}

$\mathrm{PaO}_{2}$, arterial oxygen partial pressure; $\mathrm{PaCO}_{2}$, arterial blood carbon dioxide partial pressure; $\mathrm{SaO}_{2}$, arterial oxygen saturation .

\section{Discussion}

Humidified effect of artificial airway high-flow humidification oxygen therapy is superior to that of respiratory humidification therapy in patients undergoing tracheotomy. Although both oxygen therapy devices can be used for patients with tracheotomy, the observation group and the control group were respectively treated with different active warming and humidifying oxygen therapy systems for oxygen therapy. The results in Table I show that the sputum viscosity was altered between $48 \mathrm{~h}$ and 7 days following oxygen therapy. The sputum viscosity of the control group gradually increased, the airway humidification rate decreased, and the sputum viscosity grade different significantly compared with that in the observation group $(\mathrm{P}<0.05)$. Warming and humidification can improve the comfort of patients with non-invasive ventilation (1). Patients undergoing nasal oxygen therapy retain the warming and humidifying function in the upper respiratory tract, however, the generation of condensed water in the pipeline can reduce patient comfort and compliance, which means respiratory humidification therapy devices are preferred in patients who use nasal high-flow humidification oxygen therapy (10-13) and are mainly used in patients with acute heart failure and hypoxemic respiratory failure $(14,15)$. In order to prevent the formation of condensed water, the pipeline and the extension pipe joints use water-permeable and airtight technology, which reduces the relative humidity of the delivered gas but improves the comfort and compliance of patients with nasal high flow oxygen therapy. However, when used for tracheotomy patients, a decrease in relative humidity may result in the thickening of endotracheal secretions, which in turn increases the risk of catheter obstruction (1).

As patients undergoing tracheotomy lose the warming and humidifying function of the upper respiratory tract, all inhaled gas needs to be compensated for the heat and moisture lost through the warming humidifier. An ideal high-flow humidification oxygen therapy device can meet the demand of the patient's peak flow rate, and ensures the generated air flow through the humidifier reaches the temperature and humidity of the normal human airway $(44 \mathrm{mg} / \mathrm{l}$, relative humidity $100 \%$, gas temperature $\left.37^{\circ} \mathrm{C}\right)(1,2,16)$. The artificial airway high-flow humidification oxygen therapy system used a Fisher \& Paykel MR850 humidifier and a RT308 breathing circuit equipped with a ventilator. This device is preferred for use in artificial airway patients. When the invasive mode is selected, the gas between the outlet of the humidifier and the Y-type interface is heated to $40^{\circ} \mathrm{C}$, and is then attenuated to $37^{\circ} \mathrm{C}$ by exending the pipe joint. The temperature of the inhalation gas of the patient is $37^{\circ} \mathrm{C}$, and the relative humidity reaches $100 \%$ to ensure the effective discharge of secretions in the artificial airway (1). Reports show that the inhalation of humidified gas can affect the ciliary movement of respiratory epithelial cells, and the incidence of lower respiratory tract infection can increase with decreased airway humidification (17-19). As shown in Table II, 
the number of new lung infections in the control group was increased 7 days after oxygen therapy compared with the number in the observation group, and this difference was statistically significant $(\mathrm{P}<0.05)$. The differences in airway humidification between the two groups may result in abnormality of the secreted discharge with consequent pulmonary infection establishing. The artificial airway high-flow humidification oxygen therapy system was superior to the respiratory humidification therapy instrument in patients undergoing tracheotomy.

Appropriate high-flow humidification oxygen therapy equipment can be selected according to the time requirement of the humidification oxygen therapy. Researchers have used T-tube and high-flow oxygen therapy for patients with long-term tracheotomy following cardiothoracic surgery, and showed that high-flow humidification oxygen therapy increased oxygenation when long-term mechanical ventilation intermittent training was used (3). As the results in Table III show, the difference in $\mathrm{PaO}_{2}$ and $\mathrm{SaO}_{2}$ between the two groups was not significant within $48 \mathrm{~h}$ of oxygen therapy $(\mathrm{P}>0.05)$, however, the difference was significant between $48 \mathrm{~h}$ and 7 days after oxygen therapy $(\mathrm{P}<0.05)$. As the control group patients had insufficient airway humidification and poor drainage after $48 \mathrm{~h}$, this may have caused airway obstruction, atelectasis and pulmonary infection and affected the patient's oxygenation index and ventilation effect, eventually contributing to the poor prognosis of patients (20). The artificial airway humidification oxygen therapy system supplied a satisfactory airway humidification effect for a long duration in the observation group, and ensured patient ventilation safety. It is clear that appropriate high-flow humidification oxygen therapy equipment can be selected according to the duration that the patient is treated with oxygen therapy. If the tracheotomy patient can breathe without a ventilator within $48 \mathrm{~h}$, either the artificial airway high-flow humidification oxygen therapy system or the respiratory humidification therapy instrument can be used for oxygen therapy; if the tracheotomy patients are able to self-breathe for $>48 \mathrm{~h}$, it is recommended that an artificial airway high-flow humidification oxygen therapy system is used for oxygen therapy.

Constant-velocity high-flow gas is essential for the safe use and humidification effect of the artificial airway high-flow humidification oxygen therapy closed suction system. Studies have suggested that the problem of an additional ineffective cavity and airway resistance during the use of an active warming humidification device should be considered, as it may cause negative reactions including hypopnea and respiratory muscle fatigue (21). Regarding the different types of Venturi valves used in clinical practice, it is not possible to monitor the gas flow rate of high-flow oxygen therapy devices. In order to ensure that the patient's inspiratory flow rate requirements are met and to avoid hypoventilation, clinical researchers use Venturi valves for high-flow humidification oxygen therapy and connect the tracheotomy mask or T-tube connector at the suction end. When the output gas flow rate of the oxygen therapy device is insufficient to meet the maximum inspiratory flow rate of the patient, ambient air (oxygen concentration $21 \%$, temperature $24-26^{\circ} \mathrm{C}$, humidity $40-60 \%$ ) can enter from the expiratory hole of the mask or T-tube joint. However, this increases the chance that the inhalation gas may be mixed with air which has not been warmed and humidified, resulting in the actual oxygen concentration and humidity being reduced. Therefore, the present study used the automatic pressure regulating oxygen flow meter to maintain the output gas flow rate $\geq 401 / \mathrm{min}$, providing a basis for the combined use of oxygen therapy equipment and a closed suction system. The artificial high-flow humidification oxygen therapy closed suction system can provide the same constant-speed high-flow gas as the respiratory humidification therapy device, and it reduces airway resistance and prevents side effects including hypoventilation and respiratory muscle fatigue. Furthermore, it ensures the gas inhaled by the patient is fully humidified by the heating humidifier without reducing the oxygen concentration. As shown in Table III, there was no significant difference in $\mathrm{PaCO}_{2}$ between the two groups $(\mathrm{P}>0.05)$.

However, the present study is not without limitation. It did not consider several factors that have the possibility to influence the results in the control and observation groups, including the duration of incubation, the status of nutrition (e.g., albumin), immunosuppressive status (e.g. diabetes and immunosuppressive agents) and the administration of antibiotics.

In conclusion, due to the clinical situation, a large number of patients require long-term indwelling tracheotomy catheters for oxygen therapy and expectoration, and the equipment available to satisfy the long-term high-flow humidification oxygen therapy requirements of these patients is limited. In the present study, two types of active warming humidification oxygen therapy equipment of equal quality, but with different design features, were compared for their humidification and ventilation effects in oxygen therapy for patients with tracheotomy. It was found that the artificial airway high-flow humidification oxygen therapy closed suction system was more suitable for the long-term oxygen therapy of the patients with tracheotomy than the respiratory humidification therapy instrument. With lower equipment and material costs, it can improve airway humidification and oxygen therapy effects and reduce lung infection.

\section{Acknowledgements}

Not applicable.

\section{Funding}

The present study was supported by the Shenzhen's Sanming Project Foundation of China (grant no. SZSM201612011).

\section{Availability of data and materials}

The datasets used and/or analyzed during the current study are available from the corresponding author on reasonable request.

\section{Authors' contributions}

Performed the literature review: YM; conducted research: YM, SY, PL and XXH; analyzed the data: YL, PL and YY. All authors read and approved the final manuscript. 


\section{Ethics approval and consent to participate}

The present study was approved by the Research Ethics Boards and experimental procedures were approved by the Ethics Committee of the Second People's Hospital of Shenzhen. Written informed consent was provided by all participants.

\section{Patient consent for publication}

Not applicable.

\section{Competing interests}

The authors declare that they have no competing interests.

\section{References}

1. American Association for Respiratory Care, Restrepo RD and Walsh BK: Humidification during invasive and noninvasive mechanical ventilation: 2012 . Respir Care 57: 782-788, 2012.

2. O'Driscoll BR, Howard LS, Earis J, Mak V, British Thoracic Society Emergency Oxygen Guideline Group; BTS Emergency Oxygen Guideline Development Group: BTS guideline for oxygen use in adults in healthcare and emergency settings. Thorax 72(Suppl 1): ii1-ii90, 2017.

3. Corley A, Edwards M, Spooner AJ, Dunster KR, Anstey C and Fraser JF: High-flow oxygen via tracheostomy improves oxygenation in patients weaning from mechanical ventilation: A randomised crossover study. Intensive Care Med 43: 465-467, 2017.

4. Soto-Ruiz KM, Peacock WF and Varon J: The men and history behind the Venturi mask. Resuscitation 82: 244-246, 2011.

5. Knaus WA, Draper EA, Wagner DP and Zimmerman JE: APACHE II: A severity of disease classification system. Crit Care Med 13: 818-829, 1985.

6. Yancy CW, Jessup M, Bozkurt B, Butler J, Casey DE Jr, Drazner MH, Fonarow GC, Geraci SA, Horwich T, Januzzi JL, et al: ACCF/AHA guideline for the management of heart failure: A report of the American College of Cardiology Foundation/American Heart Association Task Force on Practice Guidelines. J Am Coll Cardiol 62: e147-e239, 2013.

7. Del Sorbo L, Vendramin A and Mehta S: High flow oxygen therapy in adult critically ill patients. Minerva Anestesiol 83: 402-411, 2017.

8. Lopez-Vidriero MT, Charman J, Keal E, De Silva DJ and Reid L: Sputum viscosity: Correlation with chemical and clinical features in chronic bronchitis. Thorax 28: 401-408, 1973.
9. Kalil AC, Metersky ML, Klompas M, Muscedere J, Sweeney DA, Palmer LB, Napolitano LM, O'Grady NP, Bartlett JG, Carratalà $\mathrm{J}$, et al: Management of adults with hospital-acquired and ventilator-associated pneumonia: 2016 clinical practice guidelines by the infectious diseases society of america and the american thoracic society. Clin Infect Dis 63: e61-e111, 2016.

10. Stéphan F, Barrucand B, Petit P, Rézaiguia-Delclaux S, Médard A, Delannoy B, Cosserant B, Flicoteaux G, Imbert A, Pilorge C, et al: High-flow nasal oxygen vs noninvasive positive airway pressure in hypoxemic patients after cardiothoracic surgery: A randomized clinical trial. JAMA 313: 2331-2339, 2015.

11. Miguel-Montanes R, Hajage D, Messika J, Bertrand F, Gaudry S, Rafat C, Labbé V, Dufour N, Jean-Baptiste S, Bedet A, et al: Use of high-flow nasal cannula oxygen therapy to prevent desaturation during tracheal intubation of intensive care patients with mild-to-moderate hypoxemia. Crit Care Med 43: 574-583, 2015.

12. Delorme M, Bouchard PA, Simon M, Simard S and Lellouche F: Effects of high-flow nasal cannula on the work of breathing in patients recovering from acute respiratory failure. Crit Care Med 45: 1981-1988, 2017.

13. Papazian L, Corley A, Hess D, Fraser JF, Frat JP, Guitton C, Jaber S, Maggiore SM, Nava S, Rello J, et al: Use of high-flow nasal cannula oxygenation in ICU adults: A narrative review. Intensive Care Med 42: 1336-1349, 2016.

14. Díaz-Lobato S, Folgado MA, Chapa A and Mayoralas Alises S: Efficacy of high-flow oxygen by nasal cannula with active humidification in a patient with acute respiratory failure of neuromuscular origin. Respir Care 58: e164-e167, 2013.

15. Hughes J and Doolabh A: Heated, humidified, high-flow nasal oxygen usage in the adult Emergency Department. Australas Emerg Nurs J 19: 173-178, 2016.

16. McFadden ER Jr, Pichurko BM, Bowman HF, Ingenito E, Burns S, Dowling $\mathrm{N}$ and Solway $\mathrm{J}$ : Thermal mapping of the airways in humans. J Appl Physiol 58: 564-570, 1985.

17. Lacherade JC, Auburtin M, Cerf C, Van de Louw A, Soufir L, Rebufat Y, Rezaiguia S, Ricard JD, Lellouche F, Brun-Buisson C and Brochard L: Impact of humidification systems on ventilatorassociated pneumonia: A randomized multicenter trial. Am J Respir Crit Care Med 172: 1276-1282, 2005.

18. Cinnella G, Giardina C, Fischetti A, Lecce G, Fiore MG, Serio G Carravetta G, Dambrosio M and Fiore T: Airways humidification during mechanical ventilation. Effects on tracheobronchial ciliated cellsmorphology. Minerva Anestesiol 71: 585-593, 2005 (In English, Italian).

19. Jiang M, Song JJ, Guo XL, Tang YL and Li HB: Airway humidification reduces the inflammatory response during mechanical ventilation. Respir Care 60: 1720-1728, 2015.

20. Roux NG, Plotnikow GA, Villalba DS, Gogniat E, Feld V, Ribero Vairo N, Sartore M, Bosso M, Scapellato JL, Intile D, et al: Evaluation of an active humidification system for inspired gas. Clin Exp Otorhinolaryngol 8: 69-75, 2015.

21. Campbell RS, Davis K Jr, Johannigman JA and Branson RD: The effects of passive humidifier dead space on respiratory variables in paralyzed and spontaneously breathing patients. Respir Care 45: 306-312, 2000. 